\title{
HOW ACCOUNTING STUDENTS WITHIN THE THUTHUKA BURSARY FUND PERCEIVE ACADEMIC SUPPORT OFFERED AT ONE SOUTH AFRICAN UNIVERSITY
}

\author{
J. M. Ontong* \\ e-mail: ontongj@sun.ac.za
}

\author{
T. de Waal ${ }^{*}$ \\ e-mail: tess.dewaal@gmail.com
}

\section{W. Wentzel*}

e-mail: waylon.wentzel@gmail.com

${ }^{*}$ School of Accountancy

Stellenbosch University

Stellenbosch, South Africa

\section{ABSTRACT}

Recent academic performance of students in their chartered accountancy professional examinations has been under scrutiny by the business community in South Africa, especially examination performance amongst Black, Coloured and Indian (BCl) students (SAICA 2019a; Ryan 2019). Noting the importance of preparing higher education students for future professional examinations, this study focused on Thuthuka Bursary Fund (TBF) students in accounting. The study participants were all from $\mathrm{BCl}$ groups whilst the study aimed to gain insight into TBF students' perceptions regarding the value of two academic support structures. These structures involved additional tutorials, only offered to TBF students and individual learning program sessions, offered to all accounting students. The study aimed to understand the support format required to equip students to better prepare for examinations. Student perceptions were analysed to identify those aspects which could potentially make the offered support structures more conducive to the learning needs of students. Understanding student perceptions about the effectiveness of academic support is critical in promoting the study success of students and meeting their learning objectives. The study found that certain aspects of academic support are judged to positively contribute to students' learning, while others can be improved upon. Students seem to prefer smaller support class sizes, language-specific facilitators, support classes being scheduled during normal class hours instead of after hours, an emphasis on exam writing techniques and, to a lesser extent, course content being covered. The findings suggest more regular student feedback about the academic support offered which could result in revisions to existing support structures. Such revisions might contribute to better assistance to students, potentially increasing their performance - also in continued professional learning after graduation.

Keywords: Thuthuka, South African chartered accountants, transformation, accounting education, SAICA, Stellenbosch University 


\section{INTRODUCTION}

The South African Institute of Chartered Accountants (SAICA) has been in the spotlight in recent times due to unprecedented professional and other criticisms of its professional examinations (Ryan 2019). One of these critiques pointed to the alarmingly low pass rates of Black and Coloured (African) candidates who wrote their board exams in 2018 (Ryan 2019). A substantial variance in these pass rates was noted compared to the national average (Ryan 2019). SAICA, however, notes in a recent press release regarding one of its professional examinations, namely the Initial Test of Competence (ITC) board exams written in 2019, that its Thuthuka Bursary Fund (TBF) students had an impressive performance, achieving a pass rate in line with the overall national pass rate for this exam (SAICA 2019a). The TBF provides bursaries to African students who pursue careers as chartered accountants (SAICA 2019b; Gounden 2013). SAICA (2019b) also reports that the improved performance can be accredited to substantial time, effort and funding invested in the TBF students throughout their studies.

The Thuthuka programme has three main components that focus on the holistic development of the student, namely academic support, life skills, and community service. Within a higher education context, these focal areas aid the achievement of the main objective of the Thuthuka programme, which is to support students to complete their studies successfully and thereby potentially making a valuable contribution to society as qualified chartered accountants (Stellenbosch University 2019a).

At one South African university (Stellenbosch) certain academic support initiatives are offered to students who pursue a career in chartered accountancy and enrolled in the Bachelor of Accounting (BAcc) programme. These initiatives include the Individual Learning and Assistance Programme (ILP), available to all BAcc students, and structured tutorials (tutorials), to holders of TBF bursaries.

Against this background, the present study aimed to gain more insight into the perceptions of TBF students regarding the most influential aspects of the two academic support structures offered. Such detail might potentially be useful to facilitators or course coordinators in offering academic support more conducive to the learning needs of chartered accountancy students. The findings might also be of value to identify the merits and pitfalls of the ILP and tutorials as perceived by TBF students and thus contribute to the quality of accounting education and pass rate improvement. Such insights are essential to provide some insights into potential solutions in bridging the pass rate gap between TBF students and non-TBF African student's in future professional accountancy examinations. 


\section{Some background: The Thuthuka Bursary Fund (TBF)}

The TBF was introduced by SAICA in 2005 in order to academically support students as prospective chartered accountants (Gounden 2013). The TBF was introduced to aid the acceleration of the transformation process in this profession, as well as the development of South Africa's pool of critical and scarce skills (SAICA 2012). The bursary fund includes funding as well as a comprehensive support programme for students to study a BAcc or an equivalent degree at a SAICA-accredited university (De Jager 2014). Support offered includes mentors, tutorials, additional classes and life skills training (SAICA 2012).

\section{TBF students' academic support classes}

The ILP is an initiative that aims to increase BAcc pass rates, as well as to assist undergraduate students in attaining the results necessary for admittance to BAcc Honours, and subsequently providing further academic support during this postgraduate programme (Stellenbosch University 2019b). The ILP classes comprise one additional 50-minute lecture per week presented by lecturers in the students' language of study for each of the following subjects: financial accounting, management accounting, auditing and taxation (Stellenbosch University 2019b). During the ILP, students complete assessments with varying levels of assistance from the lecturer (Stellenbosch University 2019b). It is compulsory for TBF students at Stellenbosch University to attend both ILP classes (for the first term) and tutorials (De Jager 2014). Once individual TBF students obtain acceptable results, they are no longer obligated to attend ILP classes after the first term (Stellenbosch University 2019a).

The core objective of the tutorials offered to TBF students is to encourage the development of consistent study, the seeking of assistance, as well as practising examination techniques (Stellenbosch University 2019a). These tutorials are presented by academic trainees who participate in the SAICA Academic Traineeship Programme, or student assistants (contrary to the ILP, which is generally presented by lecturers) once a week for each of the following subjects: financial accounting, management accounting, auditing and taxation (Stellenbosch University 2019a). During tutorials students are given a question to complete as an assessment under examination typical conditions (Stellenbosch University 2019a). Thereafter, the presenter discusses the question with the students to demonstrate how it should have been answered to achieve maximum marks (Stellenbosch University 2019a). The duration of a tutorial is 90 minutes, and the class size is typically much smaller than that of an ILP due to the tutorial's exclusivity to TBF students (Stellenbosch University 2019a).

A comparison of the characteristics of the ILP and tutorials is shown in Table 1. Although the objectives of these support structures overlap in certain respects, the methodology and 
structure of the individual programmes differ. This creates the need to analyse student perceptions of both the respective programmes to identify what students perceive to be the objectives, advantages, and potential pitfalls of each academic support mechanism so that support offered could potentially be optimised and made available to all BAcc students.

Table 1: Characteristics of ILP classes and tutorials

\begin{tabular}{|c|c|c|}
\hline Characteristics & ILP & Structured tutorial \\
\hline Duration & 50 minutes & 90 minutes \\
\hline Accessibility & All BAcc students & TBF students \\
\hline Presenter & Lecturer & Student assistant or academic trainee \\
\hline Language of notes & English or Afrikaans & English or Afrikaans \\
\hline Language of presentation & English or Afrikaans & $\begin{array}{c}\text { Predominantly English, with support } \\
\text { available in Afrikaans }\end{array}$ \\
\hline
\end{tabular}

The next section of this article provides a review of existing relevant literature on the topic. The literature review is followed by explaining the research methodology as well as a discussion of the findings and conclusions of the study.

\section{LITERATURE REVIEW}

Relevant literature reveals several strategies to potentially increase academic performance among students. Examples include the use of support groups (De Jager and Bitzer 2016), peer tutoring (Colver and Fry 2016), peer mentoring (Fox and Stevenson 2006), cooperative learning (Ballantine and Larres 2009), promoting student commitment, and financial and psychological support (De Jager 2014). However, existing literature is relatively silent about students' perceptions of teaching interventions, with limited reference to perceptions of ILP initiatives and tutorials.

A study by De Jager and Bitzer (2016) found that students who participated in a support group for financial accounting perceived this involvement as positive and their pass rates improved. Smaller study groups, tutorials, and peer tutoring appear to all positively affect the performance of students and support groups (De Jager and Bitzer 2016). Colver and Fry (2016) surveyed undergraduate students' perceptions of the usefulness of tutoring, with particular focus on first-generation university students. Their study found that universities should undertake tutoring as a highly desirable strategy to promote student success, especially in the case of first-generation university students (Colver and Fry 2016).

A review of prior literature on TBF students indicates that such students have previously been identified as of particular concern. For instance, Barac (2015) investigated the attitudes and perceptions of the first group of students to pass through the TBF programme via 
questionnaires. These perceptions were then used to analyse the cohort's view of the Thuthuka programme, and whether it sufficiently prepared them for SAICA's professional examinations and the working world (Barac 2015). Barac's study suggested that certain features were needed for a support programme to help socio-economically disadvantaged students to gain access to a restrictive labour market, and to prepare them for the SAICA board examinations. A multidimensional support programme, including social and academic support, as well as exposure to the workplace and social responsibility, was suggested accordingly (Barac 2015). Such findings were earlier mentioned by Kleeman (1994), who found that student success is significantly influenced by higher education institutions that offer academic support. This was later confirmed by a study conducted by De Jager and Bitzer (2016).

De Jager (2014) investigated TBF student perceptions via a questionnaire in order to report on factors that hinder or promote the academic success of such students. The study found that TBF students perceived support (academic, personal, and financial) as main factors that contributed to their success, followed by individual commitment (De Jager 2014). De Jager (2014) noted, consistent with a recent SAICA press release that the pass rates of TBF students are very much in line with those of their classmates. De Jager (2014) and SAICA's (2019a) findings suggest that TBF student interventions have been effective in helping these students to be academically successful over time, creating a need to inquire further into the value of tutorials and to consider whether such support should also be offered to mainstream BAcc students, given the recent scrutiny of African candidates' pass rates in their professional SAICA examinations (Ryan 2019). The latter study noted that it did not analyse students' perceptions of the specific academic support initiatives available to them.

For the purposes of the present study, TBF students at one South African university (Stellenbosch) were involved as participants. Stellenbosch University offers ILP classes and tutorials as added academic support for TBF students (Stellenbosch University 2019a), but the perceptions of students regarding the use of tutorials have not previously been investigated. The present study will thus add to the existing literature as to what students perceive to be the successes and shortcomings of such initiatives and thereby address a substantial knowledge gap.

\section{RESEARCH METHODOLOGY}

The present study generated both quantitative and qualitative data by means of questionnaires completed by the 2019 group of TBF students at Stellenbosch University. The questionnaire captured the perceptions of these students on the usefulness of the tutorials and ILP classes, including the individual characteristics of each. Students also judged the perceived effect of the 
two academic support strategies on their academic performance and learning habits.

A few limitations pertaining to the study need mention when considering the results of this study. One limitation, similar to a study by Steenkamp, Baard and Frick (2012) is that student perceptions were generated and not the actual academic performance of TBF students. Such views might thus not be a fully accurate depiction of reality. Another limitation is that the inquiry was undertaken at only one university and can thus not be generalised to other institutions. However, such findings might still influence similar academic support on offer to other chartered accountancy students within South African higher education.

The questionnaire survey employed a five point Likert-type scale to indicate agreement or disagreement with a particular statement where $5=$ fully agree; $4=$ mostly agree; $3=$ neutral; $2=$ mostly disagree; 1 = fully disagree. Furthermore, a number of open-ended questions were included and the responses analysed via simple narrative content analysis. An analysis of the survey results follows under the following headings:

- $\quad$ Students' perceived objectives and benefits of attending tutorials and ILP classes;

○ Perceived objectives of students regarding tutorials and ILP classes;

○ Students' perceived benefits with respect to attending tutorials and the ILP; and

- Additional considerations regarding student perceptions of the structure and format of tutorials and ILP classes.

\section{FINDINGS}

\section{Descriptive analysis}

Table 2 shows the demographic characteristics of the 118 participant TBF students. Registered at Stellenbosch University in 2019. The survey rendered 54 responses (46\%).

Table 2: Respondent demographic data

\begin{tabular}{|c|c|c|c|c|c|c|}
\hline \multirow{2}{*}{ Study year } & \multirow{2}{*}{$\begin{array}{c}\text { Number of } \\
\text { respondents }\end{array}$} & \multicolumn{3}{|c|}{ Gender } & \multicolumn{2}{c|}{ Education language } \\
\cline { 3 - 6 } & & Female & Male & $\begin{array}{c}\text { Prefer } \mathbf{n o t} \\
\text { to say }\end{array}$ & English & Afrikaans \\
\hline $\mathbf{1}^{\text {st }}$ year & 7 & 4 & 2 & 1 & 4 & 3 \\
\hline $\mathbf{2}^{\text {nd }}$ year & 17 & 12 & 5 & 0 & 10 & 7 \\
\hline $\mathbf{3}^{\text {rd }}$ year & 19 & 14 & 5 & 0 & 18 & 1 \\
\hline Honours & 10 & 9 & 1 & 0 & 8 & 2 \\
\hline Prefer not to say & 1 & 1 & 0 & 0 & 1 & 0 \\
\hline Total & 54 & 40 & 13 & 1 & 41 & 13 \\
\hline
\end{tabular}

Source: Authors' analysis

\section{Students' perceived objectives and benefits of attending tutorials and ILP classes}

An analysis of the data indicated a number of interesting findings regarding the objectives and 
benefits for TBF students. The reason for this thorough analysis was three-fold: (i) to determine whether students' perceived objectives were in line with the primary objectives of the tutorials and ILP classes, (ii) to determine whether students' perceived benefits aligned with their objectives in attending support classes, and (iii) to determine students' views on factors that may be hindering the achievement of such objectives and benefits. Such information assisted in establishing whether the respective academic support classes were conducive to TBF students' learning needs.

\section{Perceived objectives of students regarding tutorials and ILP classes}

Students were asked what their main objective was regarding attending tutorials and ILP classes respectively. These results are shown in Table 3.

Table 3: Main objectives of students with respect to attending the relevant academic support classes (in order of ranking)

\begin{tabular}{|ll|c|c|}
\hline \multicolumn{1}{|c|}{ Main objective } & $\begin{array}{c}\text { Tutorials } \\
\text { (n) (\%) }\end{array}$ & $\begin{array}{c}\text { ILP classes } \\
\text { (n) }(\%)\end{array}$ \\
\hline 1. & Assistance with examination techniques & $24(45 \%)$ & $31(58 \%)$ \\
\hline 2. & Assistance with course content & $15(28 \%)$ & $16(30 \%)$ \\
\hline $\begin{array}{l}\text { 3. } \\
\text { General advice about the approach to successfully }\end{array}$ & $5(9 \%)$ & $5(9 \%)$ \\
\hline 4. & Other & $9(17 \%)$ & $1(2 \%)$ \\
\hline
\end{tabular}

Source: Authors' analysis

Although the existing literature focuses on the type of support offered, such as support groups, peer tutoring and peer mentoring, limited research has been done to identify the specific type of assistance in terms of the students' needs within these support measures (De Jager and Bitzer 2016; Colver and Fry 2016; Fox and Stevenson 2006). The findings suggest that the main objective for attending both tutorials ( $45 \%$ of respondents) and the ILP classes $(58 \%$ of respondents) was to obtain assistance with examination techniques. This objective is in line with the ILP and tutorials' objectives as listed in their respective programme documents. This further suggests that assistance with examination techniques as an objective of each programme seems in to correspond with student needs. It is also noted that students listed the practising of sound examination techniques as a factor that enhanced their academic success. However, the question arises as to whether the academic support offered in these support classes is sufficiently helping the students to achieve all their stated objectives, thus suggesting that the format and structure of tutorials and ILP classes might be investigated in further detail. This issue will be addressed in the second part of reporting on the findings.

Twenty-eight percent (28\%) of the respondents indicated that they attended tutorials for 
assistance with course content while 30\% indicated that they attended the ILP classes for the same reason. Although assistance with course content is not a stated objective of the tutorials, attendance of the tutorials for assistance with course content can be regarded as a mechanism for achieving the actual objective of seeking assistance when students experience difficulties in understanding the key concepts of a module (Stellenbosch University 2019a). The ILP classes therefore promote a student support group environment similar to student support groups identified in De Jager and Bitzer (2016). From the Stellenbosch Thuthuka Internal Process Document (Stellenbosch University 2019a) it is evident that instead of spending a significant amount of time on coursework, the academic trainee or student assistant should rather demonstrate how a question should be answered. The strengthening of students' conceptual understanding of the various topics is, however, an explicit objective of the ILP (ILP General Information 2016) and the findings therefore suggest that this objective of the ILP directly corresponds with student objectives. The findings also suggest a gap between the official objectives of tutorials and the perceived objectives of students, in the sense that tutorials may not be addressing the need of students to obtain additional assistance regarding course content with sufficient rigour.

The findings further suggest that students perceive the level of coursework to be a stumbling block towards academic success. This can be linked to the finding that assistance with examination techniques and an understanding of course content is students' main objective in attending support classes. The present study therefore suggests that, in addition to the objective of the ILP of assisting students to grasp core course concepts, examination techniques need to be more prevalent in the ILP classes to enable the bridging of the learning gap between formal lectures and the practical execution of the concepts learned.

The latter finding is further supported by a student's comment on what could improve the tutorials, where one student noted that it would be preferred by the students if the tutorial presenter provide them with a brief lesson prior to them attempting the relevant question alone, and then a repeat the lesson after the students had attempted the question. This could suggest that it may be more beneficial, according to student perceptions, to receive a brief summary of the relevant course content before being required to attempt the question in examination conditions, and subsequently receiving feedback on optimal completion of the question at hand. It is noteworthy that the respondents were all exposed to both tutorials and the ILP, suggesting that the need to bridge the gap between course content assistance and examination techniques is not sufficiently addressed by the ILP format alone, thereby identifying a potential stumbling block to academic success. 


\section{Students' perceived benefits with respect to attending tutorials and the ILP}

The perceived benefits of tutorials and ILP classes are shown in Table 4. A Likert-type scale of 1 (strongly disagree) to 5 (strongly agree) was used. It is noteworthy that the mean scores for the benefits of the tutorials and ILP classes achieved the same rating score for each of the statements presented, suggesting that the perceived benefits, all other factors being equal, are the same for both initiatives regarding the statements presented.

Table 4: TBF student perceptions on aspects of tutorials and ILP classes

\begin{tabular}{|l|c|c|}
\hline \multicolumn{1}{|c|}{ Statement } & \multicolumn{2}{c|}{ Mean scores (n) } \\
\cline { 2 - 3 } & Tutorials & ILP classes \\
\hline $\begin{array}{l}\text { The support programme made me more eager to } \\
\text { participate in my various modules. }\end{array}$ & $3(n=48)$ & $4(n=53)$ \\
\hline $\begin{array}{l}\text { Attendance of, and participation in, the support programme } \\
\text { positively affected my academic performance and/or } \\
\text { results. }\end{array}$ & $4(n=47)$ & $4(n=53)$ \\
\hline $\begin{array}{l}\text { The support programme benefits my continuous learning } \\
\text { approach. }\end{array}$ & $4(n=48)$ & $2(n=53)$ \\
\hline I study enough and do not require the support programme. & $2(n=48)$ & $4(n=53)$ \\
\hline $\begin{array}{l}\text { I would still attend the support programme if it was not } \\
\text { compulsory. }\end{array}$ & $4(n=47)$ & $2(n=54)$ \\
\hline $\begin{array}{l}\text { I would benefit more if I did not attend this support } \\
\text { programme and rather studied in a study group of two to } \\
\text { five people. }\end{array}$ & $2(n=47)$ & $4(n=53)$ \\
\hline $\begin{array}{l}\text { Not having access to the memo as I attempt the question } \\
\text { enhances my learning effectiveness in the support } \\
\text { programme. }\end{array}$ & $4(n=49)$ & \\
\hline
\end{tabular}

Source: Authors' analysis

Overall, it would appear that respondents generally perceived both tutorials and the ILP classes positively. This finding is consistent with the findings of Horn and Jansen (2009); Steenkamp, Baard and Frick (2012) who found that tutorials are of high academic value. The highestscoring perceived benefits, each achieving a mean score of 4 , indicating agreement, were as follows: "Attendance of, and participation in the academic support programme positively affected my academic performance and/or results"; "I would still attend the ILP classes and tutorials if they were not compulsory"; and "Not having access to the memo as I attempt the question enhances my learning effectiveness in the academic support programme". This finding suggests that the students experience a positive impact on their academic performance and continuous learning from attending the support classes. This is consistent with literature on attendance of lectures that have found attendance to have a positive influence on academic performance (Van Walbeek 2004; Papageorgiou 2019). This highlights that teaching examination technique methods such as working out questions without a memorandum, under supervised conditions, are perceived as beneficial by the respondents. Considering that students would still attend the support classes even if they were not compulsory suggests that the 
respondents regarded their perceived benefit as outweighing the potential opportunity cost of their time commitment to the tutorials and ILP classes. This finding is further supported by both the statements asking whether students studied enough and did not require the academic support programme, as well as asking whether they would rather study on their own or in smaller groups. Each of these statements achieved a mean score of 2 (disagree), suggesting that the students clearly saw the value added by such initiatives as opposed to the more traditional method of studying on their own or in small groups. This finding supports the use of support groups as identified in De Jager and Bitzer (2016) as a value added initiative versus self-study.

When asked whether the tutorials and ILP classes made students more eager to participate in their various modules, they responded with a neutral view (mean score of 3). This suggests that regardless of the increased personal attention given to students, and as a result of smaller classes in the tutorials and ILP classes as opposed to normal lectures, this does not necessarily make students more willing or eager to participate in their modules. Such findings suggest that facilitators of academic support classes need to scrutinise their approach to these mechanisms in order to keep students engaged and motivated to participate in modules, thereby discouraging unenthusiastic students employing only the minimum effort required to pass. A suggestion for this as provided by Barac (2015) is to offer a multi-dimensional support programme which includes social and academic support and perhaps more practical engagement in the accounting profession in order to see the relevance of course content covered.

\section{Additional considerations regarding student perceptions of the structure and format of tutorials and ILP classes}

The study also aimed at generating respondents' narratives on various considerations relating to the structure and format of tutorials and ILP classes. This was done in order to add to the existing literature which primarily focuses on the effect of tutorials and rather than on specific considerations surrounding the nature and format of tutorials and ILP classes which has not been explored in depth in the current literature (Steenkamp, Baard and Frick 2015; Colver and Fry 2016). These narrated perceptions provide further perspectives on how tutorials and ILP classes can be best optimised and incorporated into the various academic support programmes in order to promote student success. Considerations discussed include scheduling, duration, volume of content covered, class size and accessibility, presenters and language of teaching and learning.

\section{Scheduling}

When asked: "What (if any) would you change in the structured tutorial format?" 36 per cent 
of the respondents suggested the only improvement would be to have these tutorials scheduled earlier in the day. Further, 87 per cent of respondents agreed with the statement that they would prefer if the tutorials were not so late in the day, and this may suggest that they would prefer the scheduling of tutorials to be similar to the scheduling of the ILP classes. The mean of the responses of this statement was 4 , indicating that the scheduling definitely needs to be addressed. The ILP classes take place during the class day, starting at varying times between 09:00 and 15:00, whereas tutorials normally start at either 15:30 or 16:00. One student indicated that the tutorial takes place during the "graveyard shift" and that they were all so tired by the time of the tutorial that it impaired their concentration, resulting in information going "in the one ear and out the other." It can therefore be concluded that the perceived learning effectiveness during tutorials could potentially increase should these tutorials be scheduled earlier in the day, similar to that of the ILP classes.

\section{Duration}

The findings further suggest that the students held varying opinions about the duration of both academic support classes. The ILP classes have an approximate duration of 50 minutes per session, whereas the tutorials are approximately 90 minutes in duration. The 90 -minute duration seems to suit the purpose that tutorials serve, since students were neutral to the statement that tutorials should be shorter in terms of time allocation (mean of 3 ).

Two students commented that the ILP classes should be "longer in time" and that the "ILP classes' duration should be 1 hour 30 minutes." Another student commented that there was sufficient time to work through the solution in a tutorial, which could suggest that there is insufficient time to do so in the 50-minute ILP. This was further evidenced by the following illustrative comments:

"ILP classes turn into lectures and addressing the question may not be attained due to time constraints."

"In a structured tutorial, we have more time to complete and discuss a question, whereas in an ILP question, which is about 50 minutes long, there is not enough time to discuss the answers."

The findings suggest that 90 minutes appear to be a better perceived duration to allow students to complete a question and receive adequate feedback on the memorandum, whereas during a 50-minute session, they only manage to complete the question. The findings therefore suggest that although the students had opposing views regarding the duration requirements of the tutorials and ILP classes, the duration of the ILP classes should be aligned with that of the tutorials. 


\section{Volume of content covered}

The findings suggest that the students perceived the tutorials to be more beneficial to them than the ILP in terms of the volume of content covered in these academic support classes. More students agreed $(33 \%)$ or strongly agreed $(27 \%)$ with the statement that the tutorials covered their subject areas sufficiently and accurately in terms of the amount of time required per subject area than the number of students who agreed $(29 \%)$ or strongly agreed $(22 \%)$ with the same statement but with respect to the ILP classes. It is suggested that this result is attributable to tutorials being substantially longer than ILP classes, which facilitates a higher volume of academic content covered per session. This finding, however, highlights a potential trade-off between duration and maintaining concentration and engagement in the support class, which presents an area for future research.

\section{Class size and accessibility}

The findings suggest that the participating students prefer the smaller and more intimate class size of the tutorials. The smaller class size of tutorials is attributable to the exclusivity of these tutorials to TBF students, whereas the ILP is available to all BAcc students. This is evident from students' general disagreement with whether they would prefer if all students were allowed to attend the tutorials, and not only TBF students. More students mostly disagreed $(n=7)$ or strongly disagreed $(n=14)$ with this statement than students who mostly agreed $(n=2)$ or strongly agreed $(n=8)$.

This was further supported by the response of students to the open-ended question on their view of the main differences between tutorials and the ILP classes. What follows illustrate the point:

\footnotetext{
"The type of interaction. In the structured tutorials there is easier access to the tutor than with the ILP."

"The ILP are larger groups and structured tutorials are more hands on because we are a smaller group of people."

"The ILP is not tailored to a small group, whereas structured tutorials are."

"Less students during a structured tutorial makes it easier to follow."
}

These comments suggest that a key consideration for planning the support classes is ensuring that there is sufficient lecturer or tutor support available to assist all students. It also suggests that an increased class size of the ILP, with only one lecturer, is a potential area that can be improved by increasing resource availability. 


\section{Presenters}

Understanding student perceptions of the presenters of tutorials and ILP classes is important in establishing whether these presenters are effective in assisting with the accomplishment of the stated objectives of the tutorials and ILP classes. The findings suggest that the respondents perceived the presenters of the tutorials, even though they were not course lecturers, as having sufficient knowledge to present these support sessions, as students gave a mean response of 4 ( $n=49)$ regarding this statement. In an open-ended question about what students perceived to be better about the ILP than the tutorials, one student responded by saying that "the lecturer presents it [the ILP] and has a better understanding of the topic and what the exam covers". Three other students out of 12 respondents in total provided similar responses to this question, indicating that many students prefer the lecturers to present these support classes, rather than academic trainees or student assistants. This was expected, and the findings suggest that students tend to have more confidence in lecturers than in academic trainees or senior students about academic matters in general. More students (40\%) disagreed with the statement that they would prefer the module lecturers to present the tutorials. The findings, with respect to who present or facilitate support sessions, thus suggest that many students prefer academic trainees or senior students to present the tutorials. Such a view may be attributed to students' primary objective of attending these support classes, namely the practising of sound examination techniques as discussed in the preceding section. These students may perceive academic trainees or student assistants to be more examination ready, and therefore to be better facilitators of learning effective examination techniques than lecturers.

\section{Language of presentation}

The findings seem to identify that tutorials presented predominantly in English is a shortcoming of this initiative. Students mostly agreed with the statement that tutorials presented in their language of learning would assist them to perform better academically, which is evident from students' mean score of $4(n=44)$ for this statement. The students also agreed with the statement by indicating that they would benefit from tutorials having language-specific presenters, as this statement achieved a mean score of $4(n=47)$. These findings thus suggest that the possibility and feasibility of parallel-medium tutorials is worthy of further investigation.

\section{CONCLUSION}

Recent publicity relating to the lower pass rates of African candidates in their SAICA professional examinations has focused the spotlight on initiatives aimed at tertiary-level support 
of these students. The existing literature on tutorials and ILP classes has placed a strong focus on the academic impact of such initiatives, however limited critical analysis of the nature and format in terms of students' views has been done to date (Horn and Jansen 2009; Steenkamp, Baard and Frick 2015). The Thuthuka programme, with its multi-faceted approach, has enabled TBF students to maintain results in professional examinations that are consistent with the overall national averages achieved. The present study generated new insights into the perceptions of TBF students at least one South African university who were exposed to two different academic support strategies. The study attempted to gauge the effectiveness of each strategy according to the lived experiences and perceptions of TBF students. It thus identified whether slightly modified versions of these strategies could be made available to mainstream chartered accountancy students to better address their perceived learning needs, and potentially provide some solutions to the gap in pass rates between TBF students and non-TBF African students.

The study findings highlighted TBF students' perceived objectives and benefits of the two support strategies and showed that practising examination techniques as a main objective to attend the support classes. This corresponds with the stated objectives of the two selected support strategies. There seems to be room for improvement as many students perceive the lack of practising sound examination techniques to be an important obstacle towards academic success. It thus appears that the performance gap could be narrowed or closed if practising examination techniques under examination condition were a greater focus area during ILP classes. Also, if tutorials could address course content to some extent, instead of focusing solely on the completion of a question, student achievement might improve. The findings therefore reinforces the suggestion that the gap in objectives could be somehow narrowed by increasingly incorporating question practising in examination conditions into the ILP classes. This creates areas for future research into performing detailed examination of the nature and format specifications of support classes, whereas the majority of existing literature has instead focused on the academic effect of such support classes (Horn and Jansen 2009; Steenkamp, Baard and Frick 2015; De Jager and Bitzer 2016).

The format and structure portion of the findings suggest that student learning could potentially increase should tutorials be scheduled during normal class hours instead of after hours, similar to the ILP. Support classes with a duration extending beyond that of a conventional lecture of 50 minutes seem preferential due to the learning opportunity presented. This allows for a summary to be presented on course content, examination techniques to be practised through individual completion of a question, and feedback presented on the optimal completion of the question at hand; all of which were identified as preferential by TBF students. 
Another reason the TBF students seemed to prefer the structure of tutorials over ILP classes is because the tutorial classes are smaller due to their exclusivity to TBF students. This seemed to aid students' perceived learning effectiveness, which could be attributed to adequate support for each student in the class. This study found that even though students placed more faith in lecturer knowledge regarding coursework, they perceived academic trainees or student assistants to have sufficient knowledge, and in some cases, to be better teachers of examination techniques due to their more recent experience in writing examinations themselves. Languagespecific tutorials were perceived to be integral to some students, and they preferred the ILP classes in this respect.

Further areas identified for future research include quantitative and qualitative analysis of TBF students' pass rates versus non-TBF African students' pass rates.

This research contributes to the existing literature by offering various suggestions that can be applied to tailor the current support classes offered, such as ILP classes and tutorials. The findings regarding various aspects, such as the format and structure, could be used to assist future course coordinators, as well as facilitators and presenters of academic support initiatives, in implementing support that is conducive to the perceived learning needs of students who are studying towards a career in chartered accountancy.

\section{REFERENCES}

Ballantine, J. and P. M. Larres. 2009. Accounting undergraduates' perceptions of cooperative learning as a model for enhancing their interpersonal and communication skills to interface successfully with professional accountancy education and training. Accounting Education: An International Journal 18(4): 387-402.

Barac, K. 2015. Helping disadvantaged students: Findings from the Thuthuka programme. Accounting Education: An International Journal 24(2): 75-101.

Colver, M. and T. Fry. 2016. Evidence to support peer tutoring programs at the undergraduate level. Journal of College Reading and Learning 46(1): 16-37.

De Jager, E. 2014. Thuthuka students' perceptions of factors influencing success. Journal of Economic and Financial Sciences 7(1): 53-72.

De Jager, E. and E. Bitzer. 2016. First-year students' participation and performance in a financial accounting support group. International Business \& Economics Research Journal (IBER) 12(4): 399-413.

Fox, A. and L. Stevenson. 2006. Exploring the effectiveness of peer mentoring of accounting and finance students in higher education. Accounting Education: An International Journal 15(2): 189-202.

Gounden, Y. 2013. Thuthuka means transformation. https://www.accountancysa.org.za/thuthukameans-transformation/

Horn, P. and A. Jansen. 2009. "Tutorial classes - why bother? An investigation into the impact of tutorials." South African Journal of Economics 77: 179-89.

Kleeman, G. L. 1994. Achieving academic success with ethnically diverse students: Implications for student affairs. NASPA Journal 31(2): 137-149.

Papageorgiou, E. 2019. "Lecture attendance versus academic performance and prior knowledge of 
accounting students: an exploratory study at a South African university." South African Journal of Higher Education 33(1): 262-82.

Ryan, C. 2019. Steep rise in failure rates among black accountancy candidates raises alarm. The Citizen . https://citizen.co.business/2104890/steep-rise-in-failure-rates-among-black-accountancycandidates-raises-alarm/

SAICA see South African Institute of Chartered Accountants.

South African Institute of Chartered Accountants. 2012. Thuthuka Bursary Fund produces first fruits. https:/www.saica.co.za/News/NewsArticlesandPressmediareleases/tabid/695/itemid/3428/ language/en-ZA/Default.aspx

South African Institute of Chartered Accountants. 2019a. Transformation initiatives are paying off, says accountancy body. https://www.saica.co.za/Portals/0/LearnersStudents/Examinations/Press release_ITC_Jan_2019b.pdf

South African Institute of Chartered Accountants. 2019b. Thuthuka. https://www.saica.co.za/ Thuthuka/tabid/4212/language/en-US/Default.aspx

Steenkamp, L., R. Baard and B. Frick. 2012. A holistic investigation into a tutor programme in firstyear Financial Accounting. Meditari Accountancy Research 20(1): 68-87.

Stellenbosch University 2019a. Stellenbosch Thuthuka Internal Process Document 2019. Stellenbosch: School of Accountancy.

Stellenbosch University 2019b. Individual Learning and Assistance Program (ILP) General information 2019, 1-2.

Van Walbeek, C. 2004. "Does lecture attendance matter? Some observations from a first-year economics course at the University of Cape Town." South African Journal of Economics 72(4): 861-83. 